\title{
PANORAMA DOS PEQUENOS PRODUTORES AVÍCOLAS DIANTE DE NOVAS TECNOLOGIAS, BIOSSEGURANÇA E EXIGÊNCIAS AMBIENTAIS
}

\author{
Noeli Pedroso Dias Dacroce* \\ Edison Luiz Leismann ${ }^{* *}$ \\ Elza Hofer ${ }^{* * *}$
}

RESUMO: A pesquisa tem por objetivo analisar, a partir da percepção dos pequenos produtores do sudoeste do Paraná, quais as suas perspectivas de retorno e custos em função das necessidades de investimentos para acompanhar a evolução tecnológica e o cumprimento das exigências da legislação ambiental. Para alcançar o objetivo proposto foi desenvolvida uma pesquisa de campo, por meio de aplicação de questionário para 70 pequenos produtores, realizada entre a primeira quinzena do mês de novembro e a primeira quinzena do mês de dezembro de 2015 e análise documental. A análise dos dados foi realizada com o uso do Excel. Para avaliar a sustentabilidade econômica dos padrões de aviários implantados no sudoeste do Paraná, foram identificados e analisados os custos de produção do produtor de frango de corte. Os resultados evidenciaram que os aviários são economicamente sustentáveis, porém dependente da receita da cama aviária. Pela análise realizada observou-se que há interesse dos pequenos produtores em se adequar as novas tecnologias, mas o mesmo não ocorre com relação à expansão das atividades, onde a sucessão familiar é apontada como principal fator limitante. A maioria dos produtores possui licença ambiental e estão adequados às normas da IN 56/2007 e IN 59/2009.

PALAVRAS-CHAVE: Agronegócio; Avicultura; Inovação; Custos e sustentabilidade.

\section{ANALYSIS OF SMALL POULTRY FARMERS IN THE WAKE OF NEW TECHNOLOGIES, BIOSAFET Y AND ENVIRONMENTAL REQUIREMENTS}

ABSTRACT: Perspectives in costs and profits within the perception of small poultry farmers are investigated in the wake of investments with regard to technology

Mestre pelo Programa de Pós-graduação Stricto sensu em Administração da Universidade Estadual do Oeste do Paraná (UNIOESTE), Brasil.

** Docente Doutor no Programa de Pós-graduação Stricto sensu em Administração da Universidade Estadual do Oeste do Paraná (UNIOESTE), Brasil

*** Docente Doutora no Programa de Pós-graduação Stricto sensu em Administração da Universidade Estadual do Oeste do Paraná (UNIOESTE), Brasil. 
and compliance to environmental requirements and legislation. A field research was undertaken by a questionnaire sent to 70 small entrepreneurs between the first fortnight of November and the first fortnight of December 2015 and by analysis of documents. Data analysis was performed by Excel. Product costs of broilers were identified and analyzed to evaluate the economic sustainability of poultry standards established in the south-western region of the state of Paraná, Brazil. Results show economically sustainable poultry farms, but dependent on the costs of chicken manure. Small poultry farmers are highly interested in acquiring new technologies which are not dependent on the expansion of activities. Family succession is the main limiting factor. Further, most poultry farmers have an environmental warrant and they comply with norms IN 56/2007 and IN 59/2009.

KEY WORDS: Agribusiness; Poultry breeding; Innovations; Costs and sustainability.

\section{INTRODUÇÃO}

O Brasil é o maior exportador de carne de frango do mundo e o segundo maior produtor. Os Estados Unidos contemplam a primeira colocação e a China a terceira posição. O Brasil assumiu o segundo lugar em dezembro de 2015 com uma produção de 13,14 milhões de toneladas de carne de frango, superando as 13,05 milhões produzidas pela China (ASSOCIAÇÃO BRASILEIRA DE PROTEÍNA ANIMAL, 2016).

Para Coutinho (2014), o agronegócio desfruta de competitividade estrutural na maioria de seus segmentos, competitividade essa não decorrente apenas de amplos recursos naturais disponíveis, mas também da competente base tecnológica e empresarial que se construiu nas últimas décadas.

Para aumentar a produção em escala é primordial a inserção de novas tecnologias. Porém, o acesso a estas tecnologias requer altos investimentos. As agroindústrias brasileiras têm buscado linhas de créditos junto ao banco BNDES (Banco Nacional de Desenvolvimento Econômico e Social) para atender estas necessidades, com taxas de juros compatíveis com a rentabilidade do setor. Novas parcerias entre produtores e agroindústrias estão sendo realizadas para construção de aviários com tecnologia de "ponta", porém essas parcerias têm sido ofertadas preferencialmente 
para médios e grandes produtores, por possuírem condições de oferecer garantias às financiadoras (USITC, 2012).

O pequeno produtor é pioneiro no sistema de integração vertical brasileiro. Todavia, infraestrutura, tanto dos aviários quanto dos equipamentos, atualmente está defasada e muitos produtores não possuem recursos financeiros para se adequar às novas tecnologias. Silva (2013) afirma que a cadeia produtiva passa por um processo de rearranjo, em que os agricultores familiares integrados menos capitalizados, com deficiências no sistema organizacional e de gestão, se retiram do mercado, para a entrada de avicultores familiares profissionalizados e avicultores empresariais.

Há também barreiras impostas pelas Instruções Normativas (IN) 56/2007 e 59/2009 do Ministério da Agricultura, Pecuária e Abastecimento (MAPA). A IN 56/2007 delimita uma distância mínima de 03 km para novas construções em áreas próximas de matrizeiros, frigoríficos, fábrica de ração entre outros. Piso de alvenaria dos estabelecimentos avícolas "reprodutores" é uma das determinações estabelecidas pela norma IN 59/2009, para facilitar a limpeza e desinfecção, onerando o custo de construção dos galpões.

$\mathrm{O}$ crescimento da atividade e a preocupação com a proteção do meio ambiente motivaram a criação de leis ambientais objetivando a redução dos impactos ambientais decorrentes de novos empreendimentos bem como a regularização das atividades existentes. O Instituto Ambiental do Paraná (IAP) é o órgão responsável para liberar licenças ambientais (licença prévia, licença instalação e licença operação) aos empreendedores.

Aumento da renda de países subdesenvolvidos, preço atrativo com relação a outras proteínas de carne (bovina, suína etc.) disponíveis no mercado, fator conveniência, aumento do consumo interno e alta projeção de aumento populacional, são alguns dos fatores que impulsionam a agroindústria brasileira a buscar novas parcerias (avicultores produtores de frango de corte) pelo sistema de integração. Diante desse cenário de alta competitividade, revela-se a importância de identificar as perspectivas dos pequenos produtores avícolas em função das exigências de investimentos tecnológicos e o cumprimento das exigências da legislação ambiental, o qual neste estudo destaca-se o licenciamento ambiental da atividade avícola.

Perante este cenário qual a perspectiva do pequeno produtor permanecer 
na atividade avícola diante da necessidade de implantação de novas tecnologias e ao mesmo tempo atender as exigências legais? Os aviários padrões implantados no sudoeste do Paraná são capazes de subsidiar o produtor no campo? Doravante destes questionamentos, o objetivo da pesquisa foi analisar a partir da percepção dos pequenos produtores do sudoeste do Paraná, quais as suas perspectivas de retorno e custos em função das necessidades de investimentos para acompanhar a evolução tecnológica e o cumprimento das exigências da legislação ambiental.

\section{REVISÃO TEÓRICA}

\subsection{AGRONEGÓCIO BRASILEIRO E SUA ATRIBUIÇÃO NA CADEIA GLOBAL DE ABASTECIMENTO ALIMENTAR}

O Brasil é um país privilegiado com vasta extensão de terras férteis e clima favorável, cujos atributos o colocam como um dos maiores produtores de alimentos do mundo. Todavia a pujança do agronegócio brasileiro e sua posição no cenário mundial como o maior exportador de álcool, açúcar, café, suco de laranja, soja, carne bovina e carne de frango tem preocupado e atraído a atenção de vários países (PEREIRA; MANGUALDE, 2011).

O relatório 2015 da Organização para a Cooperação e Desenvolvimento Econômico (OECD) e Organização das Nações Unidas para Agricultura e Alimentação (FAO), projeta para o Brasil um cenário de crescimento agrícola favorável, em que coloca o país na posição de maior exportador mundial agrícola em 2024. Este crescimento será atribuído ao aumento de terras cultiváveis, cerca de 1,5\% ao ano e alta produtividade.

Para Brandt (2015), a conjuntura que vive a agricultura é dada pela sua relevância no contexto econômico do país, o grau de participação no Produto Interno Bruto (PIB). No Brasil, o setor produtivo agrícola se divide em duas vertentes, a produção de capital-intensivo e de grande escala e de propriedades agrícolas tradicionais, formados por milhares de pequenos produtores produzindo para o sustento ou para comunidades locais. 
A avicultura é um setor forte do agronegócio brasileiro. Esta atividade não se resume apenas na produção de carne de frango, mas envolve uma organizada cadeia produtiva formada por matrizes, ovos, produção de pintos, manejo e engorda até o processamento e comercialização dos produtos finais (SAAB, 2009). Concomitante a esta atividade se sustentam as indústrias de ração, máquinas e equipamentos para a produção e processamento da carne.

O Brasil se mantém entre os maiores produtores e exportadores de carne (aves, suíno e bovino) do mundo. Esta posição deve se manter pelo melhor preço da carne em virtude da desvalorização do real perante o dólar, redução do custo alimentar (grande oferta de grãos), melhoramento genético e nutricional (OECD; FAO, 2015). Deste modo, aumentando ainda mais a vantagem competitiva em relação aos concorrentes mundiais.

Todavia, o crescimento pode ser prejudicado por deficiências estruturais na economia, infraestrutura (portos, rodovias...) ineficiente, alta carga tributária, processos administrativos burocráticos e redução de recursos à pesquisa. Mesmo diante desses desafios o Brasil pode manter-se como principal eixo de oferta na cadeia global de abastecimento alimentar (SARTI; HIRATUKA, 2010).

\subsection{MODERNIZAÇÕES TECNOLÓGICAS, INOVAÇÃO E SISTEMAS DE CRÉDITO DISPONÍVEL}

Há aproximadamente três a quatro décadas não havia muitas máquinas no campo e defensivos agrícolas, o que demandava muita mão de obra, os denominados "boias-frias". A denominada Revolução Verde chegou ao Brasil com o propósito de maximizar a produção em curto período (BORGES; SANTOS, 2013). Porém, este processo de mecanização custou a muitos produtores a perda de suas terras para bancos por altas taxas de juros. Outro aspecto negativo foi a degradação do meio ambiente por meio da aplicação de grande variedade de agrotóxicos.

Com o mercado cada vez mais competitivo e a necessidade de atender as demandas mundiais e internas, torna-se indispensável a produção em escala aliadas a altas tecnologias. Na concepção de Kakimoto (2011), eficiência e eficácia na produção são fatores fundamentais para garantir a permanência do produtor no mercado. 
Desse modo, as inovações tecnológicas adotadas pelo produtor são fatores determinantes para elevar a competitividade e essencial para definir sua posição no setor. Para Morilhas (2012), a inovação põe as empresas à frente de seus concorrentes e conduz ao desiquilíbrio do mercado.

Na visão de Belusso e Hespanhol (2010), a atividade avícola requer atualizações constantes. $\mathrm{O}$ acesso ao crédito condiciona o início e a manutenção dos produtores nesta atividade, pois a produção de frangos é alvo de uma indústria que ao longo dos anos ampliou a escala e incorporou novas tecnologias, ou seja, é uma atividade que requer constantes atualizações e altos investimentos. A maioria dos produtores não possui recursos para se adequar e necessitam recorrer às linhas de financiamentos. A disponibilidade de financiamentos de longo prazo oportuniza empreendimentos de grande escala, o que fomenta o processo de crescimento econômico (SANT'ANNA; BORÇA JUNIOR; ARAUJO, 2009).

Entre as diversas linhas de créditos ofertadas pelo sistema financeiro destacamos o Programa de Modernização da Agricultura e Conservação de Recursos Naturais (MODERAGRO). Este programa, segundo o BNDES (2015), tem por objetivo

Apoiar e fomentar os setores da produção, beneficiamento, industrialização, acondicionamento e armazenamento [...] produtos da avicultura [...].Entre os itens financiáveis evidenciamos os recursos disponíveis a construção, instalação e modernização de benfeitorias; investimentos necessários ao suprimento de água, alimentação e tratamento de dejetos relacionados às atividades que se dediquem à exploração de criação animal amparadas pelo MODERAGRO e obras decorrentes da execução de projeto de adequação sanitária e/ou ambiental relacionado às atividades constantes do objetivo deste Programa (BNDES, 2015).

Nesta linha de crédito o juro é de 8,75\% ao ano, em que 100\% dos itens são financiáveis no período de dez anos incluindo os três anos de carência. Os recursos para empreendimento individual é de até $\mathrm{R} \$ 800.000,00$ (oitocentos mil reais) por cliente e para empreendimento coletivo é disponibilizado até $\mathrm{R} \$ 2.400 .000,00$ (dois milhões e quatrocentos mil reais) respeitando o limite individual por participante. As garantias no financiamento de máquinas e equipamentos isolados devem ser constituída pela propriedade fiduciária ou pelo penhor sobre os bens objeto do financiamento, em que deve ser mantido até final da liquidação do contrato (BNDES, 2015). 
Há também disponível neste período de 2015-2016 o Programa de Incentivo à Inovação Tecnológica na Produção Agropecuária (INOVAGRO), que tem por objetivo o incentivo à implementação tecnológica, boas práticas agropecuárias e de gestão rural. Os recursos disponíveis são de $\mathrm{R} \$ 1.000 .000,00$ (um milhão de reais) por beneficiário individual ou $\$ \$ 3.000 .000,00$ (três milhões de reais) para empreendimento coletivo respeitando o limite individual. Esta linha de crédito tem juros de $7,5 \%$, com prazo de dez anos para pagar incluindo os três anos de carência e exige as mesmas garantias do programa Moderagro (FRANCA; RAMOS, 2015).

O Brasil tem variadas linhas de crédito de longo prazo que objetiva o acesso a inovações tecnológicas para incremento da produção e boas práticas ambientais, Entretanto ainda é considerado um país de nível de crédito baixo com relação a outros países em desenvolvimento como China, Malásia e Tailândia (SANT'ANNA; BORÇA JUNIOR; ARAUJO, 2009). Segundo o Instituto de Economia Agrícola (IEA), houve redução de $13,3 \%$ dos recursos direcionados a investimentos programados para 2014/2015 com relação ao período anterior. Contudo, foram mantidos por meio do Programa Inovagro, medidas para incentivar a inovação tecnológica para a avicultura, suinocultura, os hortigranjeiros e a pecuária de leite (FRANCA; RAMOS, 2015).

\subsection{BIOSSEGURANÇA}

Os consumidores estão cada dia mais exigentes com relação à qualidade dos alimentos que chegam a sua mesa. Estas exigências instigam as autoridades públicas a adotarem medidas reguladoras e normas técnicas que garantam a oferta de produtos seguros (DEMATTÊ FILHO, 2014). Sistemas de rastreabilidade na indústria de alimento como medida de segurança atende as exigências dos consumidores e resguarda o mercado de aves.

Deste modo, a Agência Nacional de Vigilância Sanitária (Anvisa) estabelece medidas de biossegurança o qual se define pela "condição de segurança obtida por um conjunto de ações destinadas a prevenir, controlar, reduzir ou eliminar riscos inerentes às atividades que possam comprometer a saúde humana, animal e o meio ambiente" (ANVISA, 2015). 
O governo brasileiro vem realizando diversas ações para mitigar as preocupações sobre a segurança das aves brasileiras perante os mercados globais no intuito de aumentar a competitividade das exportações brasileiras. Entre elas a certificação de área livre de gripe aviária (FAEP, 2015).

De acordo com FAEP (2015), o Brasil se encontra em uma posição vulnerável, pois se um único caso de gripe aviária ocorresse, por exemplo, em Rondônia comprometeria toda sanidade avícola do país, fechando as portas do mercado internacional. No intuito de mudar este cenário o Mapa aprovou a Instrução Normativa $\mathrm{n}^{\mathrm{o}} 21$, de 21 de outubro de 2014 que estabelece as normas técnicas de Certificação Sanitária da Compartimentação da Cadeia Produtiva Avícola das granjas de reprodução, de corte e incubatórios, de galinhas ou perus, para a infecção pelos vírus de influenza aviária - IA e doença de Newcastle - DNC (IN 21, 2014).

A IN 21/2014 é de caráter facultativo e tem por finalidade em "reconhecer e atestar subpopulação de aves com status sanitário diferenciado, por meio da adoção de procedimentos adicionais de biosseguridade, vigilância epidemiológica, supervisões e auditorias" (IN 21, 2014).

O modelo proposto prevê a rastreabilidade total, ou seja, forma-se um complexo industrial, composto por indústria frigorífica, fábrica de ração e avicultores integrados, transformando em "compartimento", com controle total dos insumos utilizados, como ração, água, produtos biológicos, equipamentos, medicamentos, genéticos e outros materiais, bem como a tramitação de pessoas e veículos que poderão circular no local. Desse modo, mesmo que ocorra um surto de Influenza na unidade vizinha, aquele complexo poderia continuar exportando normalmente. Estados como Santa Catarina, Goiás, Mato Grosso e Mato Grosso do Sul possuem diversas unidades em processo de certificação, porém no Paraná não constam registros de solicitação de certificação. Alto custo de implantação e treinamento, dificuldade de atender as normas estabelecidas pelo Mapa e o tempo de implantação, podem ser alguns dos fatores que impactam no baixo índice de adesão das empresas (FAEP, 2015).

Segundo relatos técnicos evidenciados pela pesquisa de Silva (2013), após o período de crise ocasionado em 2000, os avicultores sofreram períodos de pressão das agroindústrias para se adequar às exigências sanitárias dos aviários, decorrentes 
de imposições do mercado internacional de carne de aves. Os técnicos informavam aos avicultores que os aviários não seriam mais alojados caso não atendessem às novas normas, e por outro lado, se atendessem as exigências receberiam uma bonificação de $25 \%$ sobre o rendimento do lote (produção de aves alojadas). Neste contexto, fica evidenciada a falta de controle que os avicultores possuem sobre suas atividades, inclusive a decisão de permanência ou não no empreendimento.

\subsection{GESTÃO RURAL SUSTENTÁVEL E EXIGÊNCIAS LEGAIS AMBIENTAIS}

No passado, o crescimento da produção agrícola ocasionou danos nos recursos terrestres e aquáticos por práticas de gestão inadequadas no intuito de aumentar a produtividade. A externalização envolve o controle de recursos produtivos. Na concepção de Leismann (2009, p. 180), "a atividade de qualquer agente econômico pode afetar indiretamente uma série de outros agentes [...] tudo depende e está relacionada a tudo". Pesquisas revelam que no período de 1961 a 2011 a produção global de cereais cresceu quase $200 \%$, embora a área cultivada tenha representado aumento de $8 \%$ (FAO, 2014), evidenciando a externalidade positiva decorrente de "processos integrados de pesquisas, crescente geração de tecnologias que aumentam o controle de atores externos (empresas, bancos, indústrias) sobre o processo de trabalho agrícola" (THEODOROVITZ, 2011).

A agricultura e a pecuária são de longe os maiores consumidores de água. Juntos são responsáveis por $13,5 \%$ da emissão de gases de efeito estufa do mundo, também são considerados um dos principais agentes do desmatamento; sendo insustentável sua atual demanda sobre os recursos hídricos globais (FAO, 2014). Os efeitos negativos dessa externalidade sobre o rendimento das culturas são mais lesivos e sucessivos do que quaisquer impactos positivos que a produção mundial vier a produzir.

A partir da resolução da Secretaria de Estado de Meio Ambiente (SEMA) 24, promulgada em 14 de julho de 2008, passou a se exigir licença ambiental para avicultura comercial que compreende: granjas, incubatórios, postura comercial, postura de ovos férteis, gansos, avestruz, perus e frangos. O licenciamento é estabelecido pelo porte do empreendimento (SEMA, 2008): 
- até 1.500 (micro) - Isento de Licença Ambiental

- 1.501até 2.500 (porte mínimo)- Licença Ambiental Simplificada (LAS)

- Os aviários de 2.501 até 5.000 (porte pequeno); 5.001 até 10.000 (porte médio); 10.001 até 40.000 (porte grande) e o maior que é de 40.000 (excepcional), deverão primeiramente solicitar a Licença Prévia (LP), posteriormente a Licença de Instalação (LI) e finalmente a licença de operação (LO).

Os empreendimentos já instalados antes da promulgação da lei poderão solicitar Licença de Operação de Regularização (LOR) com 1.501 a 2.500 e Licença Ambiental Simplificada de Regularização (LASR) para os acima de 2.501 .

Os valores da licença ambiental são determinados de acordo com porte do empreendimento associado ao seu potencial poluidor.

A busca pela sustentabilidade rural é complexa e desafiadora. Para que ocorra, necessariamente deverá haver o equilíbrio de três aspectos: econômico, social e o ambiental. As boas práticas agrícolas além de preservar os recursos naturais, também podem aumentar a produtividade gerando lucro aos produtores garantindo sua subsistência. A capacitação de funcionários e condições dignas de trabalho conforme prevê a legislação trabalhista também devem ser consideradas. Neste sentido, a sustentabilidade rural existirá se esses três segmentos estiverem equilibrados (TAGUCHI, 2014).

\section{METOdOLOGIA}

O trabalho se caracteriza como pesquisa de campo, exploratório-descritiva de abordagem qualitativa. O estudo de campo possui maior profundidade e apresenta grande flexibilidade. O pesquisador realiza seus estudos no local em que os fenômenos ocorrem, propiciando maior entendimento das regras, costumes e convenções, assim, torna-se maior a probabilidade dos sujeitos oferecerem respostas mais confiáveis (GIL, 2002). Para coleta de dados foram aplicados questionários para 70 pequenos produtores avícolas entre a primeira quinzena do mês de novembro e a 
segunda semana do mês de dezembro de 2015 e análise documental. Na concepção de Vergara (2004), uma investigação documental é realizada por meio de documentos conservados em departamentos públicos e privados de qualquer natureza, ou pessoais, anais, circulares, regulamentos entre outros. Deste modo a investigação se deu a partir de análise de Contrato Particular de Parceria Avícola, buscando identificar as exigências de sanidade e biossegurança impostas pela empresa integradora aos integrados.

A amostra de 70 produtores avícolas foi determinada pelo critério de acessibilidade, representando 19\% do universo de 361 integrados produtores de frango da empresa "X", situada no sudoeste do Paraná. Os sujeitos da pesquisa foram os avicultores produtores de frango tipo "griller", o qual é abatido aos 28 dias de idade com um peso médio de 800 a 1.300 gramas, destinado principalmente ao mercado externo (AVICULTURA INDUSTRIAL, 2013). Os questionários semiestruturados foram aplicados pelos técnicos da empresa "X", os quais foram orientados a relatar aos respondentes, quanto à relevância do estudo e a importância da participação do produtor, porém não obrigatória, ressaltando a preservação do anonimato.

Os resultados foram analisados com o uso do Excel. Contudo, foi projetada a receita e os custos de produção por lote de aviários padrões implantados no sudoeste do Paraná. Os dados dos custos foram extraídos do site da FAEP, referente ao mês de novembro de 2015, cujos dados são alimentados pelas informações coletadas nos sindicados dos avicultores do sudoeste do Paraná. Assim, por estes dados foi analisado se a atividade é economicamente viável e se justifica o investimento em novas tecnologias ou a expansão da atividade de forma a subsidiar o pequeno produtor no campo.

\section{RESULTADOS E DISCUSSÃO}

\subsection{ANÁLISE DE SUSTENTABILIDADE ECONÔMICA}

O padrão de aviário mais utilizado pelos pequenos produtores é 1.200 metros. Na Tabela 1é apresentada a ficha técnica dos aviários padrões implantados na região sudoeste do Paraná com os respectivos dados para análise. 
Tabela 1. Ficha técnica do sistema de produção de aviários frango de corte do Sudoeste - PR

\begin{tabular}{lrrrr}
\hline Tamanho do aviário & $\begin{array}{c}100 \times 12 \\
(1.200 \mathrm{~m})\end{array}$ & $\begin{array}{c}125 \times 12 \\
(1.500 \mathrm{~m})\end{array}$ & $\begin{array}{c}125 \times 14 \\
(1.750 \mathrm{~m})\end{array}$ & $\begin{array}{c}150 \times 16 \\
(2.400 \mathrm{~m})\end{array}$ \\
\hline Sistema de alimentação & Automático & Automático & Automático & Automático \\
\hline Idade de abate-dias & 28,5 & 28,5 & 28,5 & 28,5 \\
Intervalo entre lotes-dias & 12 & 12 & 12 & 12 \\
Dias p/ limpeza-aviário & 25 & 25 & 25 & 25 \\
Peso ave para abate & 1,5 & 1,5 & 1,5 & 1,5 \\
No lotes p/ troca da cama & 18 & 18 & 18 & 18 \\
Número de lotes ano & 8,85 & 8,85 & 8,85 & 8,85 \\
Alojamento-aves/lote & 20.400 & 25.500 & 29.750 & 48.000 \\
Aves p/ & 18,10 & 18,10 & 18,10 & 20,00 \\
Mortalidade (\%) & 2,80 & 2,80 & 2,80 & 2,95 \\
No aves entregues p/lote & 21.112 & 26.390 & 30.788 & 46.584 \\
Salário projetado produtor & $1.023,84$ & 1.023 .84 & $1.023,84$ & $1.023,84$ \\
Vlr. Pago por cabeça R\$ & 0,370 & 0,370 & 0,370 & 0,370 \\
Vlr. Instal. nova - R\$ & $153.313,00$ & $183.263,00$ & $209.604,00$ & $412.287,00$ \\
Vlr. Equip. novo-R\$ & $135.768,38$ & $152.561,23$ & $174.058,88$ & $325.975,89$ \\
Vlr. Total - aviário R\$ & $289.081,38$ & $335.824,23$ & $383.662,88$ & $738.262,89$ \\
\hline
\end{tabular}

Fonte: (FAEP, 2015), adaptada pelos autores

Os aviários avaliados são de alimentação automática, com idade de abate de 28,5 dias, contendo um intervalo de alojamento entre os lotes de 12 dias. Durante o ano é dado um período de 25 dias para limpeza (lonas laterais e teto). São previstos 8,85 lotes por ano e a cama é retirada após 18 lotes.

Na Tabela 2 é apresentada a receita e o custo estimado por lote referente a quatro padrões de aviários implantados no sudoeste do Paraná. 
Tabela 2. Demonstração de resultado por lote

\begin{tabular}{lrrrr}
\hline Tamanho do aviário & $\begin{array}{l}100 \times 12 \\
(1.200 \mathrm{~m})\end{array}$ & $\begin{array}{l}125 \times 12 \\
(1.500 \mathrm{~m})\end{array}$ & $\begin{array}{r}125 \times 14 \\
(1.750 \mathrm{~m})\end{array}$ & $\begin{array}{r}150 \times 16 \\
(2.400 \mathrm{~m})\end{array}$ \\
\hline 1. Receita & $\mathbf{8 . 2 8 1 , 0 5}$ & $\mathbf{1 0 . 3 1 0 , 2 8}$ & $\mathbf{1 2 . 0 2 3 , 6 5}$ & $\mathbf{1 8 . 2 7 9 , 0 2}$ \\
1.1 Rec. frango de corte & $7.811,44$ & $9.764,23$ & $11.391,60$ & $17.236,08$ \\
1.2 Rec. com venda da cama & 430,00 & 506,44 & 592,44 & $1.003,33$ \\
1.3 Rec. frango p/ consumo & 39,61 & 39,61 & 39,61 & 39,61 \\
\hline 2. Custo variável do produtor & $\mathbf{5 . 0 3 8 , 0 2}$ & $\mathbf{5 . 7 4 4 , 3 1}$ & $\mathbf{6 . 3 6 5 , 3 2}$ & $\mathbf{8 . 2 5 5 , 1 5}$ \\
\hline 3. Depreciações & $1.915,28$ & $2.233,77$ & $2.529,87$ & $4.401,98$ \\
\hline 4. Custo operacional (2+ 3) & $\mathbf{6 . 9 5 3 , 3 0}$ & $\mathbf{7 . 9 7 8 , 0 8}$ & $\mathbf{8 . 8 9 5 , 1 9}$ & $\mathbf{1 2 . 6 5 7 , 1 3}$ \\
\hline 5. Remuneração s/capital & $1.003,54$ & $1.165,30$ & $1.330,37$ & $2.541,26$ \\
6. Custo fixo (3 + 5) & $\mathbf{2 . 9 1 8 , 8 2}$ & $3.399,07$ & $3.860,24$ & $6.943,24$ \\
\hline 7. Custo total (4 + 5) & $\mathbf{7 . 9 5 6 , 8 4}$ & $\mathbf{9 . 1 4 3 , 3 8}$ & $\mathbf{1 0 . 2 2 5 , 5 6}$ & $\mathbf{1 5 . 1 9 8 , 3 9}$ \\
\hline 7.1 Custo total- $\$$ \$cab & 0,377 & 0,346 & 0,332 & 0,326 \\
\hline $\mathbf{8 . ~ S a l d o ~ s / ~ c u s t o ~ t o t a l ~ ( 1 ~ - ~ 8 ) ~}$ & $\mathbf{3 2 4 , 2 1}$ & $\mathbf{1 . 1 6 6 , 9 0}$ & $\mathbf{1 . 7 9 8 , 0 9}$ & $\mathbf{3 . 0 8 0 , 6 3}$ \\
\hline 9. Saldo sem rec. cama & $\mathbf{- 1 0 5 , 7 9}$ & $\mathbf{6 6 0 , 4 6}$ & $1.205,65$ & $2.077,3$ \\
\hline 10. Saldo s/custo total-anual & $\mathbf{2 . 8 6 9 , 2 6}$ & $\mathbf{1 0 . 3 2 7 , 0 7}$ & $\mathbf{1 5 . 9 1 3 , 1 0}$ & $\mathbf{2 7 . 2 6 3 , 5 8}$ \\
\hline
\end{tabular}

Fonte: (FAEP,2015), adaptada pelos autores

Os resultados apontaram que os padrões de aviários analisados são economicamente sustentáveis. Entretanto, se fosse desconsiderada a receita secundária (cama) o aviário padrão 1.200 metros apresentaria um prejuízo de $\mathrm{R} \$-105,79$ por lote. Os outros padrões analisados apresentaram lucratividade sem a receita da cama, porém fica evidenciado o grau de importância da receita secundária com relação à receita líquida da atividade. O que representava um incremento à renda no início do sistema de integração vertical no Brasil que passou a ser fundamental para o empreendimento. Fator evidenciado por Caldas (2014) em que aponta em sua pesquisa que nenhum produtor conseguiria superar seus custos e alguns até não se manteriam no mercado em médio e longo prazo sem a receita da cama aviária.

Há uma margem ínfima entre o custo de produção de $\mathrm{R} \$ 0,377$ (Tabela 2) por cabeça e o valor pago pela integradora de $\mathrm{R} \$ 0,370$ (Tabela 1) por cabeça no 
padrão de 1.200 metros ao qual se distancia de acordo com o aumento da produção. $\mathrm{O}$ fato de as agroindústrias possuírem o total controle dos custos de produção dos aviários lhes permite avaliar e remunerar apenas o suficiente para que o avicultor não entre em regime falimentar e deixe de fornecer a matéria-prima (ARAÚJO et al., 2008). Para a projeção dos custos de mão de obra foi estimado o valor de $\mathrm{R} \$$ 1.023,84 como base salarial do produtor, entretanto se o aviário estivesse sob contrato de parceria, onde o valor percebido é de $20 \%$ sobre o valor da receita, o valor do salário do parceiro seria $\mathrm{R} \$ 1.562,28$ (7.811,44 x 20\%), deste modo o aviário de 1.200 metros apresentaria prejuízo de $\mathrm{R} \$$ - 214,23 (-1.562,28 + 1.023,84 + 324,21). Diante do exposto, conclui-se que este padrão de aviário não comporta um funcionário e tampouco estimula o avicultor a permanecer no campo.

Para Belusso e Hespanhol (2010), a capacidade de produção constitui uma variável de fundamental importância para o êxito econômico dos produtores. Muitas vezes a margem reduzida força o avicultor a aumentar a escala de produção, no entanto, a possibilidade de aumentar a capacidade produtiva está aliada à opção particular do avicultor e às condições de custear o investimento.

\subsection{ANÁLISE DAS PERSPECTIVAS DOS PEQUENOS PRODUTORES AVÍCOLAS}

\subsubsection{Perfil dos pequenos produtores avícolas}

A pesquisa buscou identificar o perfil do pequeno produtor rural, quanto aos anos na atividade avícola, estado civil, faixa etária, filiação e escolaridade, conforme é demonstrado no Gráfico 1. 


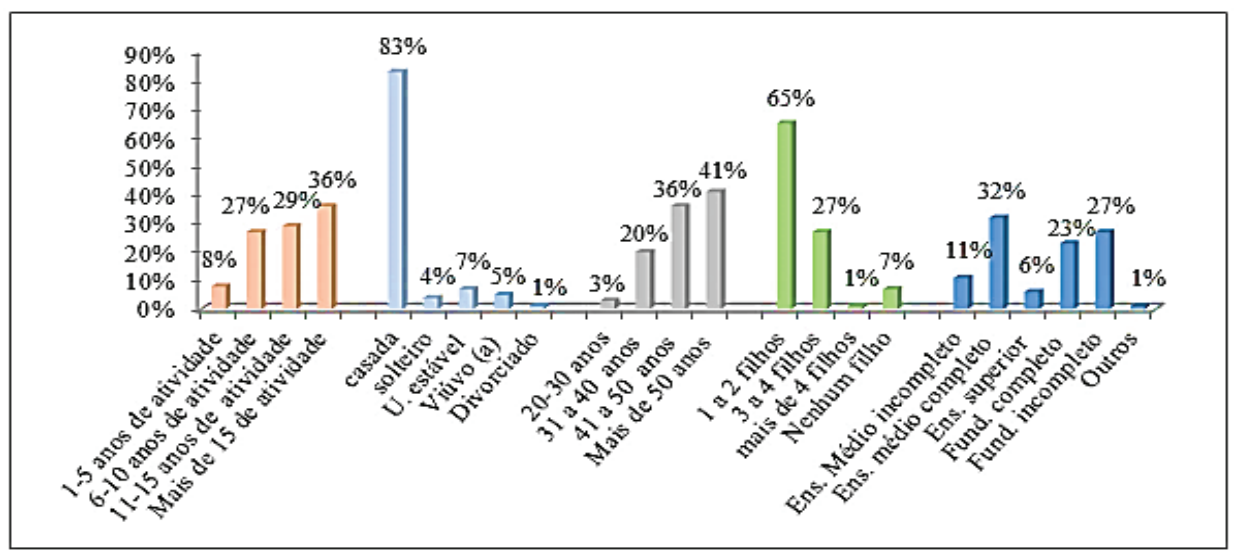

Gráfico 1. Caracterização dos produtores avaliados Fonte: Dados da pesquisa

A maioria dos avicultores avaliados possui mais de 15 anos na atividade avícola. É casado, faixa etária acima de 50 anos e possui entre um e dois filhos. O grau de instrução predominante é ensino médio completo. Garcia (2004) identificou em seu estudo a faixa etária do avicultor do Paraná entre 31-40 anos (36,7\%), com ensino fundamental incompleto (57,9\%). A pesquisa apresentou uma evolução nestes 11 anos com relação ao grau de instrução. Um fator importante na atividade, pelas complexidades do manejo de produção, o nível de sofisticação de alguns equipamentos dos aviários, o gerenciamento da atividade e até mesmo pela necessidade de conhecimento das regras dos contratos firmados com integradoras. Na concepção de Belusso e Hespanhol (2010), tanto a experiência profissional quanto o grau de instrução dos produtores podem influenciar o desenvolvimento das atividades nos estabelecimentos rurais.

Na Tabela 3 é demonstrado o perfil do produtor quanto à quantidade de terras, a metragem dos aviários onde os frangos ficam alojados e a mão de obra utilizada na produção de frango de corte. 
Tabela 3. Área das propriedades e dos aviários e tipo de mão de obra empregada

\begin{tabular}{l|l|l|l|l|l}
\hline $\begin{array}{c}\text { Área da propriedade } \\
\text { (alqueires) }\end{array}$ & \multicolumn{1}{|c|}{$\%$} & \multicolumn{1}{|c|}{$\begin{array}{c}\text { Área do aviário } \\
\left(\mathrm{m}^{2}\right)\end{array}$} & \multicolumn{1}{|c|}{$\%$} & \multicolumn{1}{|c}{ Mão de obra } & \multicolumn{1}{c}{} \\
\hline Até 5 alqueires & $26 \%$ & $900 \mathrm{~m}$ & $10 \%$ & $100 \%$ familiar & $84 \%$ \\
\hline Entre 6 e 10 & $33 \%$ & $1200 \mathrm{~m}$ & $61 \%$ & Possui funcionário & $16 \%$ \\
\hline Entre 11 e 15 & $16 \%$ & $1500 \mathrm{~m}$ & $10 \%$ & - & - \\
\hline Mais que 15 & $25 \%$ & Mais que $1500 \mathrm{~m}$ & $19 \%$ & - & - \\
\hline Total Geral & $100 \%$ & Total Geral & $100 \%$ & Total Geral & $100 \%$ \\
\hline
\end{tabular}

Fonte: Dados da pesquisa

Quanto à área de terras, 33\% dos produtores avícolas respondentes possuem entre 6 a 10 alqueires. Há a predominância de aviários com 1.200 m e o indicador de mão de obra familiar é de $84 \%$. Garcia (2004) cita que a mão de obra familiar no Estado do Paraná está presente em 94,4\% dos empreendimentos avícolas. Belusso e Hespanhol (2010) revelam em sua pesquisa que mesmo com as mudanças explícitas como produção em escala pela crescente quantidade de aviários por produtor, ampliação e adequações dos aviários e o predomínio de aviários climatizados, contudo, ainda prevalece a mão de obra familiar (65\%). O que se observa é que a redução da mão de obra familiar está condicionada à busca da menor dependência da atividade avícola. Muitos pequenos produtores arrendaram suas atividades e foram para o centro urbano, empregar toda a família em vagas no frigorífico, construção civil ou comércio local, vislumbrando alguns benefícios como plano de saúde, férias e $13^{\circ}$ salário.

\subsubsection{Dimensão - Tecnológica e Recursos Financeiros}

Pela dimensão tecnológica e recursos financeiros buscou-se demonstrar o padrão de tecnologia utilizado nos aviários e seu interesse quanto à adequação e expansão, bem como o rendimento familiar, o qual é apontado no Gráfico 2. 


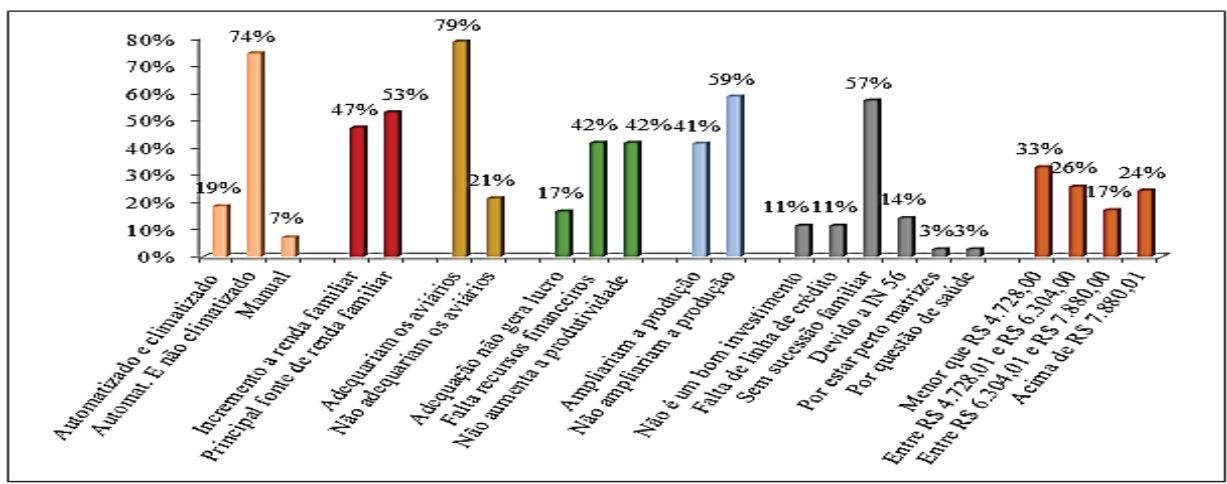

Gráfico 2. Dimensão tecnológica e recursos financeiros Fonte: Dados da pesquisa

A pesquisa revela que $74 \%$ dos aviários são automatizados e não climatizados. Dentre os respondentes 53\% têm a avicultura como a principal fonte de renda apontando um rendimento familiar acima de $\mathrm{R} \$ 7.880,00$ (24\%). Nos últimos anos a busca pela diversificação na atividade vem aumentando. Belusso e Hespanhol (2010) apontam em sua pesquisa realizada no oeste do Paraná que 31\% dos avicultores ou são profissionais liberais ou são pequenos empresários urbanos que visualizaram a implantação de aviários como um investimento rentável. O lucro incerto, falta de autonomia no negócio e dificuldades de negociação são alguns dos fatores que podem influenciar na permanência do avicultor na atividade, culminando o risco da perda de avicultores para outros setores.

Com relação à adequação tecnológica, $79 \%$ dos produtores demonstraram interesse em se adequar às exigências. Dentre os $21 \%$ que não se adequariam, $84 \%$ dos respondentes citaram a ausência de crédito e o fato que adequações não aumentam a produtividade como principais limitantes. Quanto à ampliação da capacidade produtiva, 59\% dos produtores não possuem interesse em construir novos aviários, sendo a sucessão familiar o principal fator impeditivo mencionado. A permanência do jovem no campo depende essencialmente de políticas públicas adequadas, que sejam mais compatíveis às necessidades da juventude, disponibilizando espaços para interlocução e efetivação das demandas necessárias à permanência da juventude no campo, de forma a prosseguir com a nobre tarefa de produzir alimentos diversificados e com qualidade, o qual é considerado papel estratégico da agricultura familiar (FRITZ, 2012). 
Para Demattê Filho (2014), são questionáveis os benefícios em termos de qualidade de vida e de melhora socioeconômica de produtores, relacionados a altos investimentos exigidos para que possam permanecer na atividade. Belusso e Hespanhol (2010) citam que além dos recursos financeiros algumas barreiras podem impossibilitar o processo de expansão: indisponibilidade de mão de obra, escassez de água, falta de área para construir, entre outros fatores como também, atender às exigências ambientais (distância de fonte, rios...) e biossegurança (distância de abatedouros, matrizes, estradas).

\subsubsection{Dimensão - Leis Ambientais e Biossegurança}

No Gráfico 3 demonstram-se os dados da pesquisa em percentual com relação às leis ambientais, biossegurança e ao Plano de Gerenciamento de Resíduos Sólidos (PGRS).

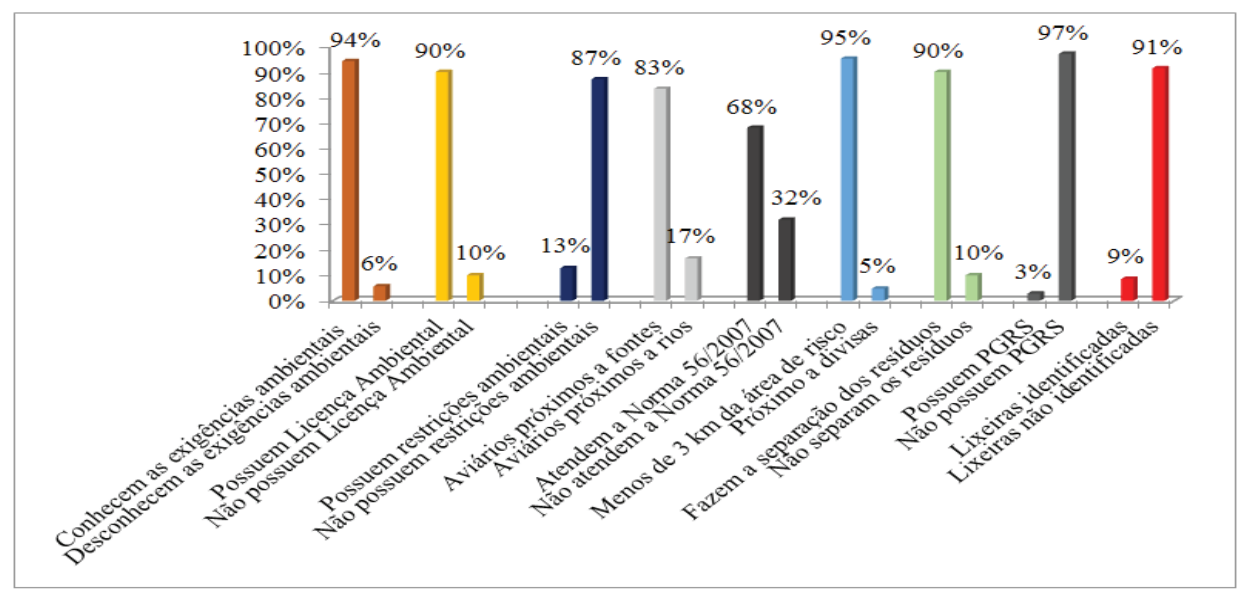

Gráfico 3. Dados com relação às leis ambientais e biossegurança Fonte: Dados da pesquisa

No gráfico acima, colocar em minúsculo as palavras "licença ambiental".

Com relação às questões ambientais, $94 \%$ dos avicultores afirmaram conhecer as normas inerentes à atividade e $90 \%$ têm licença ambiental. Dos produtores questionados, 87\% não possuem restrição ambiental. Dos $13 \%$ que possuem res- 
trição 83\% é proveniente à proximidade do aviário a fontes de água. Referente ao gerenciamento dos resíduos, $90 \%$ dos respondentes fazem a segregação de seus resíduos sólidos. Contudo, dos que realizam a segregação apenas 9\% possuem lixeiras identificadas e os mesmos não fazem a quantificação. Foi identificado que $97 \%$ dos produtores não possuem plano de gerenciamento dos resíduos sólidos e a coleta é efetuada pela prefeitura uma vez por mês. Embora os produtores tenham consciência das boas práticas e manejos sustentáveis os deixam em segundo plano.

A maioria dos produtores analisados atende à norma IN 56/2007 (68\%) e cerca de $95 \%$ dos 32\% que possuem restrição, estão situados a menos de $3 \mathrm{~km}$ da área de risco.

As integradoras utilizam mecanismos que propõe motivar o avicultor a atender as normas. Verificou-se por meio de análise documental que há uma cláusula contratual no Instrumento Particular de Contrato de Produção Integrada em Terminação de frangos/perus de corte, onde a integradora (agroindústria) premia o integrado (avicultor) com incremento de $10 \%$ sobre o rendimento do lote, caso sejam cumpridos os quesitos referentes à qualidade final percebida no produto: os princípios de bem-estar animal, rastreabilidade, biossegurança, biosseguridade, segurança alimentar, ambiental e sanitária. Estes quesitos são avaliados pela aplicação de questionário de avaliação da adequação estrutural/procedimentos, antes do abate das aves pelos técnicos extensionistas da integradora.

Por outro lado, há também uma cláusula contratual o qual permite a integradora (agroindústria) a cobrar do integrado as perdas das aves por contaminação ou "negligência de manejo". Este procedimento abre margem à cobrança de uma responsabilidade imputada pela agroindústria ao produtor que pode não ser precedente.

Um extensionista atende uma determinada quantidade de avicultores, o qual pode levar uma bactéria de um aviário para outro, caso não cumpra os cuidados necessários. Fato relatado por um dos produtores da empresa "X"; houve contaminação por Salmonella gallinarum. $\mathrm{O}$ avicultor cita que dias após a visita do técnico as aves começaram a morrer e era de conhecimento público que a empresa possuía diversos avicultores com esta bactéria. Dias após o acerto do lote lhe foi apresentado um termo de confissão de dívida o qual determinava o ressarcimento à agroindústria pela morte das aves que estavam sob a guarda do mesmo. 
O produtor expõe que possui dois aviários e que a contaminação deu-se apenas no aviário 1, onde o técnico entrou e que no aviário 2 não foi detectada a presença da bactéria. Na visão do produtor este fato reforça a teoria de que são adotados os procedimentos de biosseguridade e que houve negligência por parte do técnico extensionista.

Além da fragilidade dos produtores diante das exigências das agroindústrias, a pesquisa evidenciou também a dependência que os avicultores possuem recursos de terceiros. A receita oriunda da produção de frango de corte é suficente para subsidiar o pequeno produtor, porém apresentando alto grau de dependência da cama aviária, principalmente nos padrões de 1.200 metros. Embora o fator financeiro seja claramente um limitante de adequação e expansão da atividade, o mesmo é amenizado pelos recursos disponibilizados pelas agências de créditos. A sucessão familiar é o aspecto mais importante apontado na pesquisa no processo decisório quanto à expansão das atividades. O que se observa é que os filhos não pretendem permanecer no campo e tampouco continuar com o empreendimento, desestimulando o produtor a investir e/ou aumentar a produtividade.

\section{CONSIDERAÇÕES FINAIS}

Os resultados indicaram que os padrões de aviários analisados são economicamente sustentáveis, porém há uma estreita margem de lucro no setor, que pode ser atribuído ao fato de as agroindústrias conhecerem os custos de produção e trabalharem de forma a pagar apenas o suficiente para que a classe não caia em regime falimentar, deixando o avicultor dependente da receita da cama aviária que uma vez era tido como um incremento à renda.

Identificou-se que há uma cláusula no Contrato de Integração Avícola, o qual oportuniza as agroindústrias integradoras a imputarem a responsabilidade e cobrança aos avicultores, das aves mortas decorrentes de contaminação e "negligência de manejo". A cobrança é efetuada por meio de um Termo de Confissão de Dívida. Todavia, as contaminações podem ser decorrentes do trânsito dos técnicos extensionistas entre os aviários contaminados e não contaminados. 
O estudo pode contribuir como ferramenta de barganha para negociação com as integradoras, bem como instigar a busca da sustentabilidade econômica em longo prazo para o pequeno avicultor.

Foi identificado na pesquisa que os produtores possuem segregação dos resíduos sólidos, porém não há um plano de gerenciamento. Como proposta de pesquisa futura sugerem-se estudos em profundidade sobre o gerenciamento de resíduos sólidos na atividade rural, bem como uma proposta de plano de gerenciamento. Outra questão observada foi com relação à sucessão familiar em que o estudo poderia buscar identificar o "porquê" os jovens estão desestimulados a permanecer no campo e "como" mudar este cenário.

\section{REFERÊNCIAS}

AGENCIA NACIONAL DE VIGILÂNCIA SANITÁRIA - ANVISA. Disponível em: $<$ http://portal.anvisa.gov.br/wps/content/Anvisa + Portal/Anvisa/Inicio/Sangue + Teci$\mathrm{dos}+\mathrm{e}+$ Orgaos/Assunto $+\mathrm{de}+$ Interesse/Conceitos, + glossarios, + siglas/Biosseguranca. $>$. Acesso em: 09 out. 2015.

\section{AVICULTURA INDUSTRIAL. Brasil domina as exportações de frango halal. Dispo-} nível em: <http://www.aviculturaindustrial.com.br/imprensa/brasil-domina-as-exportacoes-de-frango-halal/20130426-085601-e600 > . Acesso em: 26 abr. 2017.

ARAÚJO, G. C. et al. Cadeia produtiva da avicultura de corte: avaliação da apropriação de valor bruto nas transações econômicas dos agentes envolvidos. Gestão \& Regionalidade, v. 24, n. 72, set./dez. 2008. Disponível em: < http://seer.uscs.edu.br/ index.php/revista_gestao/article/viewFile/95/58 > . Acesso em: 19 dez. 2015.

ASSOCIAÇÃO BRASILEIRA DE PROTEÍNA ANIMAL - ABPA. Relatório anual de atividades: Manual. São Paulo: ABPA, 2015. Disponível em: < http://abpa-br.com. br/storage/files/versao_final_para_envio_digital_1925a_final_abpa_relatorio_ anual_2016_portugues_web1.pdf $>$. Acesso em: 11 mar. 2017.

BELUSSO, D.; HESPANHOL, A. N. Evolução da avicultura industrial brasileira e seus 
efeitos territoriais. Revista Percurso - NEMO, Maringá, v. 2, n. 1 , p. 25-51, 2010. Disponível em:<http://www2.fct.unesp.br/nivaldo/Publica\%E7\%F5es-nivaldo/2010/ AVICULTURA-2010.pdf> . Acesso em: 10 out. 2015.

BANCO NACIONAL DE DESENVOLVIMENTO ECONÔMICO E SOCIAL - BNDES. Circular SUP/AGRIS No 14/2015. 2015. Rio de Janeiro. Disponível em: < http://www. bndes.gov.br/SiteBNDES/export/sites/default/bndes_pt/Galerias/Arquivos/produtos/ download/circulares/2015/15Circ014_AGRIS.pdf>. Acesso em: 27 set. 2015.

BANCO NACIONAL DE DESENVOLVIMENTO ECONÔMICO E SOCIAL - BNDES. Circular SUP/AGRIS No 08/2015-BNDES. 2015 Rio de Janeiro. Disponível em: < http:// www.bndes.gov.br/SiteBNDES/export/sites/default/bndes_pt/Galerias/Arquivos/produtos/download/circulares/2015/15Circ008_AGRIS.pdf > . Acesso em: 27 set. 2015.

BORGES, J. A. V.; SANTOS, C. E. R. O desenvolvimento sustentável nas pequenas propriedades agrícolas caracterizadas como agricultura familiar no brasil. In: SEMANA DE ECONOMIA UESB, 12., 2013, Vitória da Conquista. Anais... Vitória da Conquista, Bahia, .2013. Disponível em: < http://www.uesb.br/eventos/semana_economia/2013/anais-2013/h02.pdf> . Acesso em: 19 dez. 2015.

BRANDT, G. T. Sucessão familiar em empresa do agronegócio. 2015. 82 f. Dissertação (Mestrado Profissional em Administração) - Universidade Federal do Rio Grande do Sul, Porto Alegre, 2015. Disponível em:<http://www.lume.ufrgs.br/bitstream/ handle/10183/111797/000953686.pdf?sequence=1>. Acesso em: 25 set. 2015.

COUTINHO, L. A crise e as múltiplas oportunidades de retomada do desenvolvimento industrial do Brasil. In: MONTEIRO FILHA, D.; PRADO, L.C. D.; LASTRES, H.M.M. (Org.). Estratégias de desenvolvimento, política industrial e inovação: ensaios em memória de Fabio Erber. Rio de Janeiro: BNDES, 2014. p. 81-101.

DEMATTÊ FILHO, L.C. Sistema agroalimentar da avicultura fundada nos princípios da agricultura natural: multifuncionalidade, desenvolvimento territorial e sustentabilidade. 2014, 252 f. Tese (Doutorado em Ciências) - Universidade de São Paulo Escola Superior de Agricultura "Luiz Queiroz "Centro de Energia Nuclear na 
Agricultura, Piracicaba, São Paulo. 2014. Disponível em: < http://www.teses.usp.br/ teses/disponiveis/91/91131/tde-07112014-150141/pt-br.php>. Acesso em: 17 set. 2015.

FAEP. Os custos da avicultura. Boletim Informativo do sistema FAEP. n. 1307, p. 4-10, jun./jul. 2015. Disponível em: < http://www.sistemafaep.org.br/wp-content/ uploads/2015/06/BI1307.pdf. > . Acesso em: 18 dez. 2015.

FAO. The State of Food and Agriculture. Innovation in family farming. Rome, Italy: FAO, 2014.

FRITZ, N. L. Juventude rural e sucessão familiar: o desafio da pedagogia da alternância nas casas familiares rurais. 2012. 153 f. Dissertação (Mestrado em Políticas Públicas) - Universidade Estadual de Maringá, Maringá, PR, 2012. Disponível em: < http://www.escoladegoverno.pr.gov.br/arquivos/File/1_Producoes_Academicas/ Juventude_Rural_e_Sucessao_Familiar_o_desafio_da_pedagogia_da_ alternancia_nas_casas_familiares_rurais_Nilton_Luiz_Fritz.pdf $>$. Acesso em: 17 dez. 2015.

GARCIA, L.A.F. Economias de escala na produção de frangos de corte no Brasil. 2004. 114 f. Tese (Doutorado em ciências aplicadas) - Escola Superior de Agricultura Luiz de Queiroz, Piracicaba, São Paulo, 2004. Disponível em: < http://www.teses. usp.br/teses/disponiveis/11/11132/tde-16112004-150759/pt-br.php > . Acesso em: 16 dez. 2015.

GIL, A.C. Como Elaborar Projetos de Pesquisa. São Paulo: Atlas, 2002.

FRANCA, T.J.F.; RAMOS, R.C. Plano de Safra 2015/16: medidas para um ano difícil. IEA - Instituto de Economia Agrícola. 2015. Disponível em: <http://www.iea. sp.gov.br/out/LerTexto.php?codTexto=13709> . Acesso em: 28 set. 2015.

KAKIMOTO, S. K. Fatores críticos da competitividade da cadeia Produtiva do ovo no estado de São Paulo. 2011, 156f. Dissertação (Mestrado em Engenharia de Produção) - Centro de Ciências Exatas e de Tecnologia Departamento de Engenharia 
de Produção Programa de Pós-graduação em Engenharia de Produção, Universidade Federal de São Carlos, São Paulo. Disponivel em :<http://www.bdtd.ufscar.br/ htdocs/tedeSimplificado//tde_busca/arquivo.php?codArquivo $=5154>$. Acesso em: 27 set. 2015.

LEISMANN, E. L. Externalidades. In: ALBUQUERQUE, J. L. (Org).Gestão ambiental e responsabilidade social: conceitos e ferramentas e aplicações. São Paulo : Atlas, 2009. p. 174-193.

MAPA. Legislação - Instrução Normativa No 56/2007. Disponível em: < http:// www.avisite.com.br/legislacao/anexos/IN_56_04-12-07.pdf $>$. Acesso em: 10 ago. 2015.

MAPA. Legislação - Instrução Normativa No 59/2009. Disponível em: < http:// www.avisite.com.br/legislacao/anexos/nt_in59_20091207.pdf > . Acesso em: 10 ago. 2015.

MORILHAS, L. J. Cenários tecnológicos e os padrões de impactos econômicos, sociais e ambientais: um estudo prospectivo no setor sucroenergético brasileiro. 2012. Tese (Doutorado em Administração) - Faculdade de Economia, Administração e Contabilidade, University de São Paulo, São Paulo, 2012. Disponível em: < http:// www.teses.usp.br/teses/disponiveis/12/12139/tde-01102012-183701/.> Acesso em: 19 dez. 2015.

OECD/FAO. OECD-FAO Agricultural Outlook 2015. OECD Publishing, Paris. 2015. Disponível em: <http:/dx.doi.org/10.1787/agr_outlook-2015-en>.

PEREIRA,V. V.; MANGUALDE, M. A rotulagem ambiental no agronegócio. Revista em Agronegócios e Meio Ambiente, v. 4, n. 2, p. 267-276, maio/ago. 2011. Disponível em: $<$ http://periodicos.unicesumar.edu.br/index.php/rama/article/ view/1710/1243>. Acesso em: 26 set. 2015.

RESOLUÇÃO SEMA no 024, de 14 de julho de 2008. Disponível em: < http://www. iap.pr.gov.br/arquivos/File/Legislacao_ambiental/Legislacao_estadual/RESOLUCOES/RESOLUCAO_SEMA_24_2008_LICENCIAMENTO_AVICULTURA.pdf. $>$. Aces- 
so em 17 de outubro de 2015.

SAAB, M. S. B. L. M.; NEVES, M.F.; CLAUDIO, L. D.G. O desafio da coordenaçãoe seus impactos sobre a competitividade de cadeias e sistemas agroindustriais. R. Bras. Zootec., Viçosa, v. 38, n. spe, p. 412-422, jul. 2009 . Disponível em: < http://www.scielo.br/ scielo.php?script $=$ sci_arttext\&pid $=$ S1516 $=35982009001300041-\& \operatorname{lng}=$ en\&nrmiso >. Acesso em: 17 mar. 2017.

SANT'ANNA, A. A.; BORÇA JUNIOR, G.R.; ARAUJO, P. Q. de. Mercado de crédito no Brasil: evolução recente e o papel do BNDES (2004-2008). Revista do BNDES, Rio de Janeiro, v. 16, n. 31, p. 41-60, jun. 2009. Disponível em: < http://www.bndes. gov.br/SiteBNDES/export/sites/default/bndes_pt/Galerias/Arquivos/conhecimento/ revista/rev3102.pdf $>$. Acesso em: 27 set. 2015.

SARTI, F. et al. (Coord.). Perspectivas do investimento na indústria. Rio de Janeiro: Synergia: UFRJ, Instituto de Economia; Campinas: UNICAMP, Instituto de Economia, 2010. (Projeto PIB - Perspectiva do investimento no Brasil; v. 2). Diponível em: <https://www3.eco.unicamp.br/neit/images/stories/arquivos/pib_sintese-industria_vfinal.pdf $>$. Acesso em: 24 set. 2015.

SILVA, E. I. da. O papel da avicultura na construção do território e na reprodução social da agricultura familiar: o caso de Chapecó e quilombo no oeste catarinense. 2009. 114f. Dissertação (Ciências Agrárias ) - Programa de PósGraduação em Agroecossistemas, Centro de Ciências Agrárias, Universidade Federa de Santa Catarina, Florianópolis Santa Catarina. 2013. Disponível em: < http://bdtd. ibict.br/vufind/Record/UFSC_78a6c93fd65bc4ff980fc9a868ec486a > . Acesso em: 31 ago. 2015.

THEODOROVITZ, M. M. Um estudo sobre a configuração organizacional de gestão na agricultura familiar no agronegócio em Bela Vista do Toldo inserido na 26 Secretaria de Desenvolvimento Regional (SDR). 2011. 79 f. Dissertação (Mestrado em Desenvolvimento Regional) - Universidade do Contestado - UnC, Canoinhas, Santa Catarina. 2011. Dispoível em: <http://www.unc.br/mestrado/editais/ DISSERTACAO_MARLON_M_THEODOROVITZ.pdf>. Acesso em:19 dez. 2015.

TAGUCHI, V. O que é sustentabilidade e quando uma propriedade rural pode ser 
considerada sustentável? Globo Rural, fevereiro 2014. Disponível em:<http:// revistagloborural.globo.com/Colunas/fazenda-sustentavel/noticia/2014/02/guia-deboas-praticas-o-que-e-sustentabilidade-e-quando-uma-propriedade-rural-pode-serconsiderada-sustentavel.html> . Acesso em: 18 ago. 2015.

USITC. United States International Trade Commission Brazil: Competitive Factors in Brazil Affecting U . S . and Brazilian Agricultural Sales in Selected Third Country Markets. Abril 2012. Universidade do Contestado - UnC, Canoinhas.

Recebido em: 17/02/2016 Aceito em: 11/05/2017 